\title{
Experimental comparison of five friction models on the same test-bed of the micro stick-slip motion system
}

\author{
Y. F. Liu ${ }^{1}$, J. Li ${ }^{1}$, Z. M. Zhang ${ }^{2}$, X. H. Hu' ${ }^{2}$, and W. J. Zhang ${ }^{1,2}$ \\ ${ }^{1}$ Complex and Intelligent System Laboratory, School of Mechanical and Power Engineering, \\ East China University of Science and Technology, Shanghai, China \\ ${ }^{2}$ Department of Mechanical Engineering, University of Saskatchewan, Saskatoon, Canada \\ Correspondence to: W. J. Zhang (chris.zhang@ usask.ca)
}

Received: 18 September 2014 - Revised: 27 January 2015 - Accepted: 24 February 2015 - Published: 6 March 2015

\begin{abstract}
The micro stick-slip motion systems, such as piezoelectric stick-slip actuators (PE-SSAs), can provide high resolution motions yet with a long motion range. In these systems, friction force plays an active role. Although numerous friction models have been developed for the control of micro motion systems, behaviors of these models in micro stick-slip motion systems are not well understood. This study (1) gives a survey of the basic friction models and (2) tests and compares 5 friction models in the literature, including Coulomb friction model, Stribeck friction model, Dahl model, LuGre model, and the elastoplastic friction model on the same testbed (i.e. the PE-SSA system). The experiments and simulations were done and the reasons for the difference in the performance of these models were investigated. The study concluded that for the micro stick-slip motion system, (1) Stribeck model, Dahl model and LuGre model all work, but LuGre model has the best accuracy and (2) Coulomb friction model and the elastoplastic model does not work. The study provides contributions to motion control systems with friction, especially for micro stick-slip or step motion systems as well as general micro-motion systems.
\end{abstract}

\section{Introduction}

Micro stick-slip motion systems can provide high resolution motions yet with a long motion range. The piezoelectric stick-slip actuator (PE-SSA), which is a hybridization of the piezoelectric actuator (PEA) and the stick slip actuator (SSA), is a typical example in these systems. By hybridization, it is meant that PE and SS are complementary to each other, according to the hybridization design principle proposed by Zhang et al. (2010).

The working process of the PE-SSA is demonstrated in Fig. 1. At position (1), a voltage is applied to the PEA and leads to an (relatively slow) expansion of the PEA, which pushes the stage moving to the right. The friction between the stage and the end effectorbrings the end effector to the position (2) (stick motion). When the applied voltage is shut down quickly, the PEA contracts quickly and the slip between the end effector and stage takes place due to the inertia of the end effector, which overcomes the friction resistance. The relative displacement $S$, with respect to its initial posi- tion (1), is thus generated at position (3) (slip motion). If the aforementioned process is repeated periodically, the end effector will keep moving to the right as long as the physical system allows. The back forward motion of the end effector can also be obtained by reversing the actuation potential signal applied on the PEA.

It can be found from the aforementioned working process of the PE-SSA that the friction force between the end effector and stage plays both an active role in the forward stroke motion and a passive role in the backward stroke in the stick-slip motion system. The modeling of the friction for prediction and control of such a system is extremely important as well as difficult (Makkar et al., 2007; Li et al., 2008a). The difficulty lies in the possibility that the motion direction on the two contact surfaces may change the frictional effect (Zhang et al., 2011). Although numerous friction models have been studied in the context of macro, micro motion, such as Coulomb friction model, viscous friction model, Stribeck friction model, Dahl model, LuGre model, 


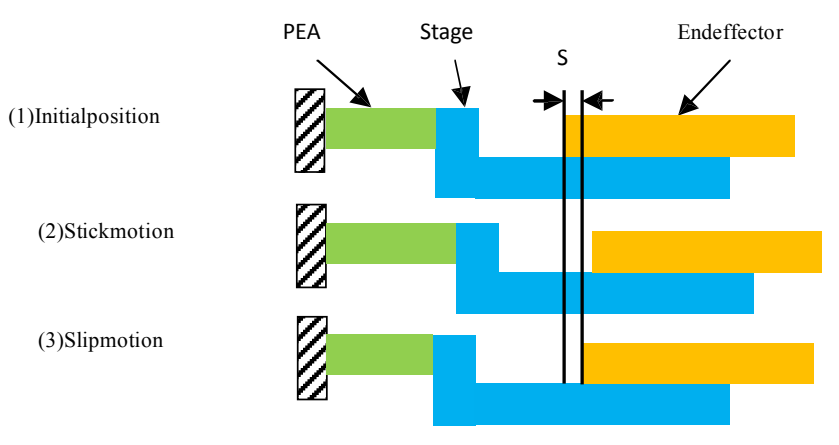

Figure 1. The working process of the PE-SSA.

and elastoplastic friction model, the performances of these models in micro stick-slip motion systems are not well understood. This paper aims to investigate the performance of different friction models inmicrostick-slip motion systems. A survey of basic friction models is presented first and five of the mare selected for comparison. A common micro stickslip motion system- the PE-SSA system which was introduced in our previous study ( $\mathrm{Li}$ et al., 2008a) is used as a testbed. Parameters in each friction model will be determined using the system identification technique. Performances of these models are then compared. Leuven and GMS models are out of the scope of the study because they are not commonly used in the step motion system such as the stick-slip motion system.

The remainder of the paper is organized as follows. Section 2 gives an overview and history of the five friction models. The mathematical descriptions of these friction models are presented in Sect. 3. The experimental setup is described in Sect. 4. Section 5 presents the analysis methodology. Section 6 presents the experimental results along with discussions, followed by conclusions in Sect. 7 .

\section{Overview of the friction models}

The first friction model is Coulomb friction model (or called Amontons-Coulomb friction model), referring to the work done by Guillaume Amontons and CharlesAugustin de Coulomb in 1699 and 1785, respectively. In the Coulomb friction model, the friction force is the function of load and direction of the velocity. Morin (1833) found that the static friction (i.e. friction at zero sliding speed) is larger than the Coulomb friction. With respect to the static friction, the Coulomb friction is also called dynamic friction. Viscous friction was later introduced in relation to lubricants by Reynolds and it is often combined with Coulomb friction model. Stribeck (1902) experimentally observed that friction force decreases with the increase of the sliding speed from the static friction to Coulomb friction. The phenomenon is thus called Stribeck effect. The integration of the Coulomb friction, viscous friction, and Stribeck effect is often an idea
Table 1. Friction characteristics captured by different models.

\begin{tabular}{lllll}
\hline & Viscous & Stribeckeffect & Pre-sliding & Hysteresis \\
\hline Coulomb & No & No & No & No \\
Viscous & Yes & No & No & No \\
Stribeck & Yes & Yes & No & No \\
Dahl & No & No & Yes & Yes \\
LuGre & Yes & Yes & Yes & Yes \\
Elastoplastic & Yes & Yes & Yes & - \\
Leuven & Yes & Yes & Yes & Yes \\
GMS & Yes & Yes & Yes & Yes \\
\hline
\end{tabular}

to obtain a more accurate friction model, which is called Stribeck model in literature.

Dahl (1968) first modeled friction as a function of the relative displacement of two contact surfaces, and it is thus called Dahl model. The model is based on the fact that friction force is dependent on the "micro motion" in ball bearings. The "micro motion", later called pre-sliding behavior, is that when the external force is not large enough to overcome the static friction, the asperities on two contact surfaces will experience deformation that results in the pre-sliding motion. The asperities form a kind of spring-damping system. When the external force is sufficiently large, the spring is broken, leading to a relative sliding between two contact surfaces. The Dahlmodel successfully describes the so-called breakaway phenomenon.

Canudas et al. (1995) developed a friction model called LuGre model, named after the two universities, namely Lund and Grenoble. LuGre model incorporates the viscous friction and Stribeck effect into Dahl model. The problem of incorporating the pre-sliding behavior in the friction model is that both Dahl and LuGre models experience "drift" when there is an arbitrarily small bias force or vibration. The reason for this drift is that both Dahl and LuGre models only include a "plastic" component in their model when they describe the pre-sliding phenomenon.

To overcome this drift, Dupont et al. (2000) proposed a friction model based on LuGre model, in which the presliding was defined as the elastoplastic deformation of asperities; i.e. the relative displacement is elastic (reversible) first and then it transits to the plastic (irreversible) stage. The model of Dupont et al. (2000) is thus called elastoplastic friction model.

Leuven friction model and generalized Maxwell-slip (GMS) model were proposed by Swevers et al. (2000) and Lampaert et al. (2002), respectively. The two models were developed based on the experimental findings that the friction force in the pre-sliding regime has a hysteresis characteristic with respect to the position. It is reported that the two models can improve the hysteresis behavior of the friction predicted with LuGre model.

The friction characteristics that are captured by the aforementioned models are listed in Table 1 . To control a dynamic 
system for high accuracy, a common sense seems to go with the friction model that can capture more friction characteristics. However, such may not always be the case. Generally speaking, for a complex dynamic system such as frictional systems, a (complete) model may be viewed as an integration of a couple of sub-models, each of which captures one or more characteristics. While being integrated, each of them may produce "side effects" to the modeling of other characteristics (Li et al., 2008b, 2009), because these characteristics are coupled, changing with time and perhaps, the physical structure of the frictional system changes as well.

\section{The mathematical description of friction models}

\subsection{Coulomb model}

Coulomb friction model is represented using the following equation:

$F= \begin{cases}F_{\mathrm{c}} \cdot \operatorname{Sgn}(\dot{x}) & \text { if } \dot{x} \neq 0 \\ F_{\mathrm{app}} & \text { if } \dot{x}=0 \text { and } F_{\mathrm{app}}<F_{\mathrm{c}}\end{cases}$

where $F$ is friction force, $\dot{x}$ is sliding speed, $F_{\text {app }}$ is applied force, $F_{\mathrm{C}}$ is the Coulomb friction force, which is defined as

$F_{\mathrm{c}}=\mu F_{\mathrm{N}}$

where $\mu$ is the Coulomb friction coefficient (or called the dynamic friction coefficient), and $F_{\mathrm{N}}$ is a normal load between two contact surfaces.

The Coulomb model is illustrated in Fig. 2a. When $F_{\text {app }}<F_{\text {c }}$, there is no sliding (i.e. $\dot{x}=0$ in the "macro" sense) between two contact surfaces, and the Coulomb friction can take any value from zero up to $F_{\mathrm{c}}$. If $\dot{x} \neq 0$, Coulomb friction only takes $F_{\mathrm{c}}$ or $-F_{\mathrm{c}}$, depending on the direction of the sliding.

Coulomb friction model is commonly used in the applications such as the prediction of temperature distribution in bearing design and calculation of cutting force in machine tools due to its simplicity. However, it is often troublesome to use the Coulomb friction model in micro motion systems because of the "undefined" friction force at $\dot{x}=0$.

\subsection{Viscous friction model}

Viscous friction model is given by

$F=k_{\mathrm{v}} \dot{x}$

where $\mathrm{F}$ is the friction force, $k_{\mathrm{v}}$ the viscous coefficient, and $\dot{x}$ the sliding speed.

The viscous friction model is illustrated in Fig. 2b. In the viscous model, the friction force is a linear equation of the sliding speed. The application of the viscous model is limited because it has a poor representation in regions where there is no lubricant (Andersson et al., 2007).

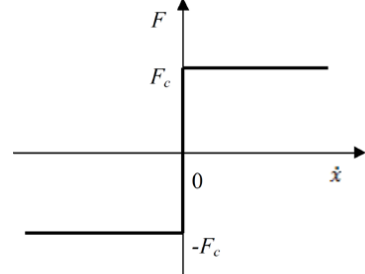

(a)

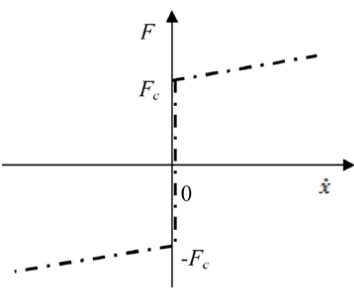

(c)

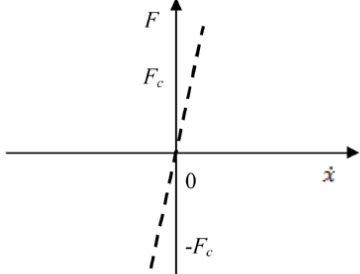

(b)

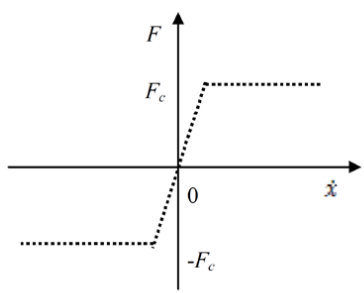

(d)
Figure 2. Friction force vs. sliding speed.

\subsection{Integrated Coulomb and viscous model}

There are two ways to combine viscous friction model and Coulomb model, leading to two different integrated Coulomb and viscous models. One is described by

$$
F=\left\{\begin{array}{ll}
F_{\mathrm{c}} \cdot \operatorname{Sgn}(\dot{x})+k_{\mathrm{v}} \dot{x} & \text { if } \dot{x} \neq 0 \\
F_{\mathrm{app}} & \text { if } \dot{x}=0 \text { and } F_{\mathrm{app}}<F_{\mathrm{c}}
\end{array} .\right.
$$

This model (Eq. 4) is illustrated in Fig. 2c. The problem with this model is that the friction force at is still "undefined". To overcome this problem, the idea is to integrate the Coulomb model and the viscous model near $\dot{x}=0$. This comes with the second model given by (Andersson et al., 2007)

$F=\left\{\begin{array}{ll}\min \left(F_{\mathrm{c}}, k_{\mathrm{v}} \dot{x}\right) & \text { if } \dot{x} \geq 0 \\ \max \left(-F_{\mathrm{c}}, k_{\mathrm{v}} \dot{x}\right) & \text { if } \dot{x}<0\end{array}\right.$.

This model (Eq. 5) is illustrated in Fig. 2d. The viscous coefficient determines the speed of the friction force transition from - to + .

\subsection{Stribeck friction model}

Stribeck friction model is described by

$F=\left(F_{\mathrm{c}}+\left(F_{\mathrm{s}}-F_{\mathrm{c}}\right) e^{-\left(\left|\frac{\dot{x}}{v_{\mathrm{s}}}\right|\right)^{i}}\right) \operatorname{Sgn}(\dot{x})+k_{\mathrm{v}} \dot{x}$

where $F$ is friction force, $\dot{x}$ Sliding speed, $F_{\mathrm{c}}$ the Coulomb friction force, $F_{\mathrm{s}}$ the static friction force, $v_{\mathrm{s}}$ the Stribeck velocity, $k_{\mathrm{V}}$ the viscous friction coefficient, and $i$ an exponent. It is clear from Eq. (6) that the Stribeck friction force takes $F_{\mathrm{S}}$ as the upper limit and $F_{\mathrm{c}}$ as the lower limit. The relation of friction versus sliding speed in Stribeck model is illustrated in Fig. 3. 


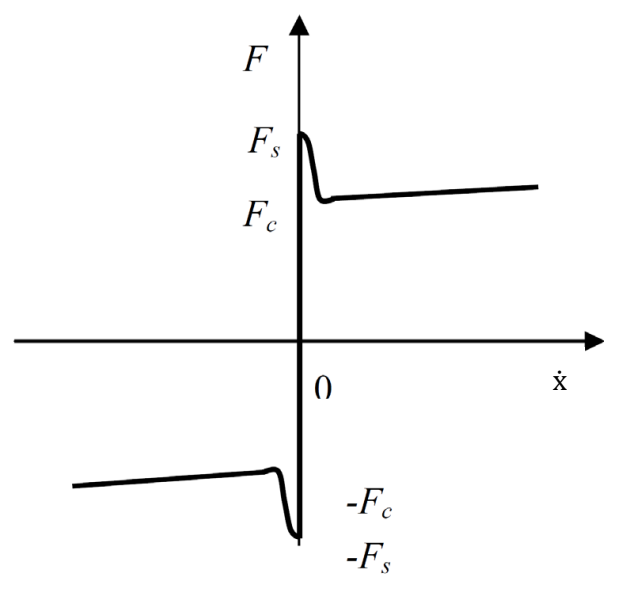

Figure 3. Stribeck friction model (Armstrong-Helouvry, 1993).

\subsection{Dahl model}

In Stribeck model, friction force is a function of the sliding speed. However, according to this model, friction force is "undefined" when it is less than $F_{\mathrm{s}}$. Dahl developed a model to describe friction at this pre-sliding stage, which is given by

$\frac{\mathrm{d} F(x)}{\mathrm{d} t}=\frac{\mathrm{d} F(x)}{\mathrm{d} x} \frac{\mathrm{d} x}{\mathrm{~d} t}$

with

$\frac{\mathrm{d} F}{\mathrm{~d} x}=\sigma_{0}\left|-\frac{F}{F_{\mathrm{c}}} \operatorname{sgn}(\dot{x})\right|^{i} \operatorname{sgn}\left(1-\frac{F}{F_{\mathrm{c}}} \operatorname{sgn}(\dot{x})\right)$

where $F$ is the friction force, $\sigma_{0}$ the stiffness coefficient, and $i$ the exponent which determines the shape of the hysteresis. In literature, Dahl model is often simplified with the exponent $i=1$ and given by

$\frac{\mathrm{d} F}{\mathrm{~d} x}=\sigma_{0}\left(1-\frac{F}{F_{\mathrm{c}}} \operatorname{sgn}(\dot{x})\right)$.

Dahl model does not describe the Stribeck effect (Canudas et al., 1995).

\subsection{LuGre model}

LuGre model has the following form (Canudas et al., 1995)

$$
\left\{\begin{array}{l}
F=\sigma_{0} z+\sigma_{1} \dot{z}+\sigma_{2} \dot{x} \\
\dot{z}=\dot{x}-\sigma_{0} \frac{\dot{x}}{g(\dot{x})} z \\
g(\dot{x})=F_{\mathrm{c}}+\left(F_{\mathrm{S}}-F_{\mathrm{c}}\right) e^{-\left(\left|\frac{\dot{x}}{v_{\mathrm{s}}}\right|\right)^{j}}
\end{array}\right.
$$

where $F$ is the friction force, $\sigma_{0}$ the contact stiffness, $z$ the average deflection of the contacting asperities, $\sigma_{1}$ the damping coefficient of the bristle, $\sigma_{2}$ the viscous friction coefficient, $x$ the relative displacement, $F_{\mathrm{c}}$ the Coulomb friction force, $F_{\mathrm{S}}$ the static friction force, $\dot{x}$ the sliding velocity, $g(\dot{x})$

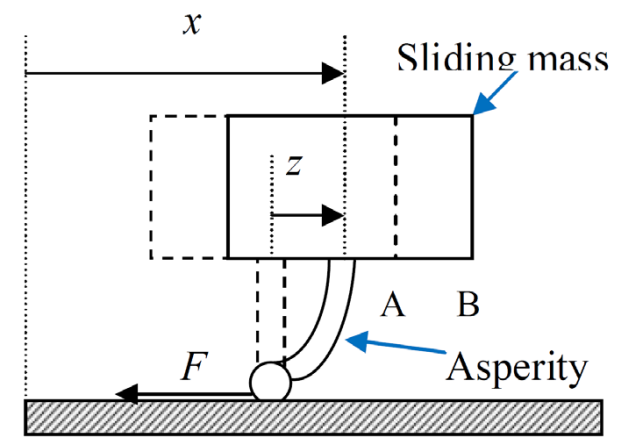

Figure 4. Illustration of deformation of asperity on the frictional surface.

the Stribeck effect, $v_{\mathrm{s}}$ the Stribeck velocity, $j$ the Stribeck shape factor ( $j=2$ is often used in the literature). LuGre model integrates pre-sliding friction $\left(\sigma_{0} z\right)$, viscous friction $\left(\sigma_{2} \dot{x}\right)$, and Stribeck effect $(g(\dot{x}))$ into one single model.

\subsection{Elastoplastic friction model}

The elastoplastic friction model is described by

$\left\{\begin{array}{l}F=\sigma_{0} z+\sigma_{1} \dot{z}+\sigma_{2} \dot{x} \\ \dot{z}=\dot{x}\left(1-\sigma(z, \dot{x}) \frac{z}{z_{\mathrm{ss}}(\dot{x})}\right)\end{array}\right.$

with

$z_{\mathrm{ss}}(\dot{x})=\frac{g(\dot{x})}{\sigma_{0}}$

$g(\dot{x})=F_{\mathrm{c}}+\left(F_{\mathrm{s}}-F_{\mathrm{c}}\right) e^{-\left(\left|\frac{\dot{x}}{v_{\mathrm{s}}}\right|\right)^{j}}$.

In Eq. (11), $\sigma(z, \dot{x})$ is used to define the zones of the elastic and plastic deformation of asperities and given by

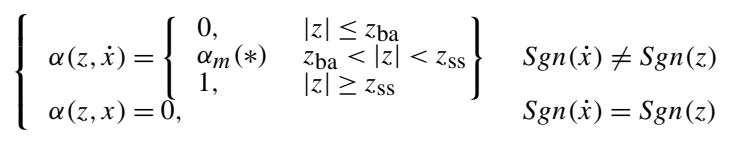

where $\operatorname{Sgn}(\dot{x})=\operatorname{Sgn}(z)$ represents that the sliding mass moves from position A to position B, as shown in Fig. 4, and $\operatorname{Sgn}(\dot{x}) \neq \operatorname{Sgn}(z)$ represents that the sliding mass moves from position $\mathrm{B}$ to $\mathrm{A}$.

According to Equation (14), when $\operatorname{Sgn}(\dot{x}) \neq \operatorname{Sgn}(z)$, $\alpha(z, \dot{x})=0$. This represents that no slip occurs; the "sliding" mass is in an elastic deformation region, or two contact objects are in a stick phase. When $\operatorname{Sgn}(\dot{x}) \neq \operatorname{Sgn}(z)$, if $|z| \leq z_{\text {ba }}, \alpha(z, \dot{x})=0$. This represents that no slip occurs; the "sliding" mass is in an elastic deformation region, or two contact objects are in a stick phase. When $\operatorname{Sgn}(\dot{x}) \neq \operatorname{Sgn}(z)$, if $z_{\text {ba }}<|z|<z_{\mathrm{ss}}, \alpha(z, \dot{x})=\alpha_{m}(*)$. This represents that elastic deformation of the asperities starts to transit to the plastic deformation, i.e. transition phase. When $\operatorname{Sgn}(\dot{x}) \neq \operatorname{Sgn}(z)$, if $|z| \geq z_{\mathrm{ss}}, \alpha(z, \dot{x})=1$. This represents that slip occurs; the 


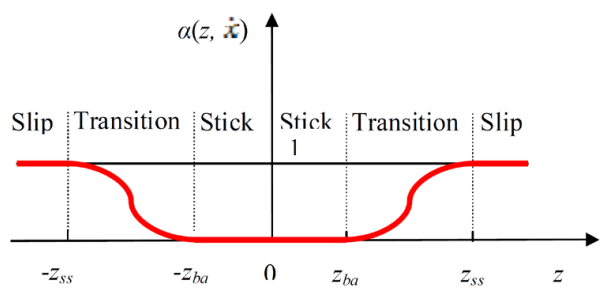

Figure 5. Dependency of $\alpha(z, \dot{x})$ on deformation of the asperity.

"sliding" mass is in a plastic deformation, or two contact objects are in a slip phase. $z_{\mathrm{ba}}$ and $z_{\mathrm{ss}}$ are given by

$0<z_{\text {ba }} \leq z_{\text {ss }}$ and $z_{\mathrm{ss}}=\operatorname{Max}\left(z_{\mathrm{ss}}(\dot{x})\right)=\frac{F_{\mathrm{s}}}{\sigma_{0}}, \dot{x} \in R$.

$\alpha_{m}(*)$ is typically in the following form:

$\alpha_{m}(*)=\frac{1}{2} \sin \left(\pi \frac{z-\left(\frac{z_{\mathrm{ss}}+z_{\mathrm{ba}}}{2}\right)}{z_{\mathrm{ss}}-z_{\mathrm{ba}}}\right)+\frac{1}{2}$.

The case when $\operatorname{Sgn}(\dot{x})=\operatorname{Sgn}(z)$ in Eq. (14) are illustrated in Fig. 5.

From Fig. 5 it can be seen that in the elastoplastic friction model, $|z| \leq z_{\text {ba }}$ is defined as the stiction zone. The stiction zone is to overcome the drift problem of Dahl and LuGre models. The transitions between stick and slip is given by $\alpha_{m}(*)$, and the slip zone is represented by $|z| \geq z_{\mathrm{ss}}$ when it returns to LuGre model.

\section{Experimental setup}

The PE-SSA prototype is shown in Fig. 6. This system is composed of 1: frames, 2: friction plates, 3: temperature sensor, 4: weights, 5: end effector, 6: displacement sensor, 7: stage, 8: wheel, 9: PEA, and 10: vibration-isolated test bed. The PEA (Model: AE0505D16) purchased from NEC/TOKIN Corp. Is connected to the frame at one end, and its other end is connected to the stage. Friction plates were placed between the end effector and stage, and they were connected with the stage by screws. The weights were used to adjust the pressure between the end effector and stage. The wheel was used to support the stage. The temperature sensors are installed inside of the stage to measure temperature change in the system, which is not used in this work. The control system for the PE-SSA was designed as an open-loop system and implemented with dSPACE and Matlab/Simulink. The system was placed on the vibration isolated test bed in order to reduce disturbance to the system. More details about this prototype can be found in our previous work (Li et al., 2008a). During the experiments, the applied voltage to the PEA was a repeating saw tooth wave with amplitude of $30 \mathrm{~V}$ and frequency of $5 \mathrm{~Hz}$. The displacements of the end effector were then measured with a KAMAN instrument (SMU 9000, Kaman) based on the eddy-current inductive principle and with a resolution of $0.01 \mu \mathrm{m}$.

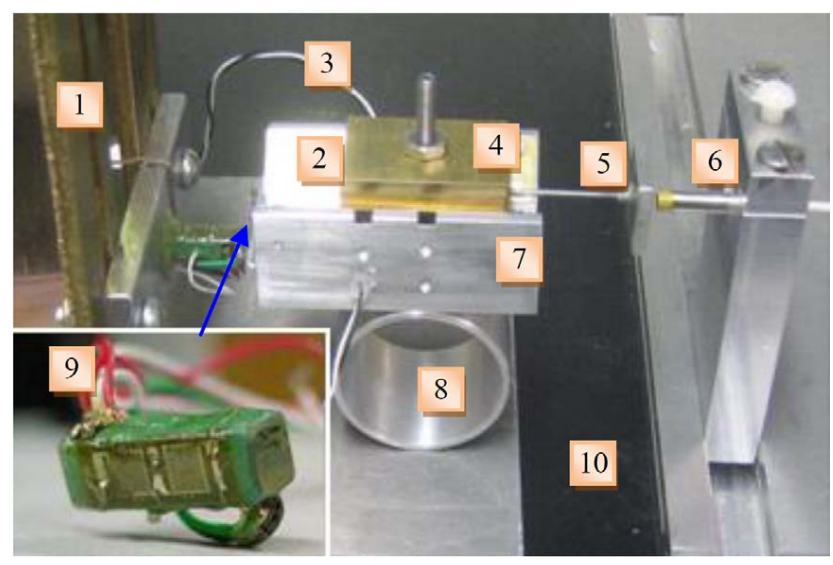

Figure 6. Experimental system of the PE-SSA (Li et al., 2008a).

\section{The method for analysis}

The method used to compare the performance of different friction models consists of the following steps.

- Step 1: get experimental data, i.e. the displacement of the PE-SSA with respect to time under a certain driven voltage and frequency.

- Step 2: model the PEA and stage and determine the parameters in the model (see Sect. 5.1).

- Step 3: model the PE-SSA by integrating the friction of the stick-slip motion into the model of the PEA and stage (see Sect. 5.2).

- Step 4: identify friction model parameters (see Sect. 5.3), including (a) use different friction models to represent friction in the PE-SSA model and (b) determine the parameters for each friction model.

- Step 5: compare the performance of the friction models in terms of their prediction of displacement, friction force, and sliding speed (i.e. relative speed between end effector and stage). The details are discussed in Sect. 6.

\subsection{Modeling of the PEA and stage}

Adriaens et al. (2000) showed that the PEA and stage can be modeled as a spring-mass-damper system which is shown in Fig. 7.

The governing equations of this spring-mass-damper system are given in Eqs. (17)-(19) as follows:

$m \ddot{x}_{\mathrm{p}}+c \dot{x}_{\mathrm{p}}+k x_{\mathrm{p}}=F_{\mathrm{p}}$ 


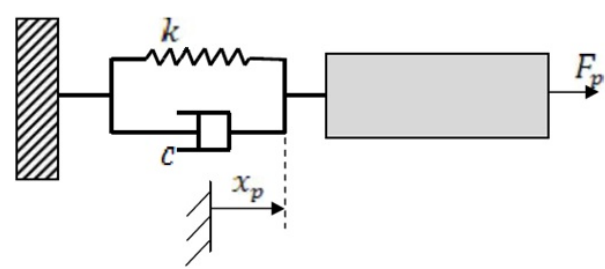

Figure 7. Physical model of the PE-SSA system (without friction) (Adriaens et al., 2000).

$$
\begin{aligned}
& \left\{\begin{array}{l}
m=\frac{4 m_{\mathrm{p}}}{\pi^{2}}+m_{\mathrm{s}} \\
c=c_{\mathrm{p}}+c_{\mathrm{s}} \\
k=k_{\mathrm{p}}+k_{\mathrm{s}}
\end{array}\right. \\
& F_{\mathrm{p}}=T_{\mathrm{em}} u_{\mathrm{p}}
\end{aligned}
$$

where $x_{\mathrm{p}}$ is the displacement of the PEA, $m_{\mathrm{p}}$ the mass of PEA, $c_{\mathrm{p}}$ the damping coefficient of PEA, $k_{\mathrm{p}}$ the stiffness of PEA, $m_{\mathrm{S}}$ the mass of stage, $c_{\mathrm{S}}$ the damping coefficient of the stage, $k_{\mathrm{s}}$ the stiffness of stage, $F_{\mathrm{p}}$ the transducer force from the electrical side, $T_{\mathrm{em}}$ the electromechanical transducer ratio, and $u_{\mathrm{p}}$ the applied voltage on the PEA. In this study, Adriaens' model is taken due to its simplicity, which was validated by our previous study (Li et al., 2008b; Kang, 2007).

Equation(17) can be further written as

$\ddot{x}_{\mathrm{p}}+2 \xi \omega_{\mathrm{n}} \dot{x}_{\mathrm{p}}+\omega_{\mathrm{n}}^{2} x_{\mathrm{p}}=K \omega_{\mathrm{n}}^{2} u_{\mathrm{p}}$

with

$$
\left\{\begin{array}{l}
\frac{c}{m}=2 \xi \omega_{\mathrm{n}} \\
\frac{k}{m}=\omega_{\mathrm{n}}^{2} \\
\frac{T_{\mathrm{em}}}{m}=K \omega_{\mathrm{n}}^{2}
\end{array}\right.
$$

where $\xi$ is the damping ratio, $\omega_{\mathrm{n}}$ the natural frequency, $K$ and the amplified coefficient. The transfer function of the springmass-damper system can be written as,

$$
G(s)=\frac{x_{\mathrm{p}}(s)}{U(s)}=\frac{K \omega_{\mathrm{n}}^{2}}{s^{2}+2 \xi \omega_{\mathrm{n}} s+\omega_{\mathrm{n}}^{2}} .
$$

In this study, the parameters $\xi$ and are $\omega_{\mathrm{n}}$ calculated from the following equations,

$$
\left\{\begin{array}{l}
\xi=\frac{\ln (\operatorname{os} \times 100)}{\sqrt{\pi^{2}+\ln ^{2}(\mathrm{os} \times 100)}} \\
\omega_{\mathrm{n}}=\frac{\pi}{T_{\mathrm{p}} \sqrt{1-\xi^{2}}}
\end{array}\right.
$$

where os is the overshoot of a step response and $T_{\mathrm{p}}$ is the peak time of a step response. The os and $T_{\mathrm{p}}$ are determined from the step response of the system. $K$ is the ratio of output and input in the steady state of the step response. In our PEA system, we have $\xi=0.2488, \omega_{\mathrm{n}}=6685.5 \mathrm{rad} \mathrm{s}^{-1}$, and $K=0.096 \times 10^{-6} \mathrm{~m} \mathrm{v}^{-1}$, and they were obtained from the measured step responses of the system.

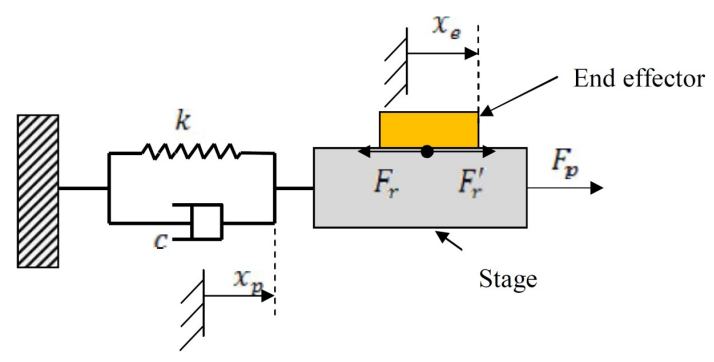

Figure 8. Physical model of the PE-SSA system (with friction) (Adriaens et al., 2000).

\subsection{Modeling of the PE-SSA}

In the PE-SSA, the friction force $F_{\mathrm{r}}$ between the end effector and stage is applied on the stage, as shown in Fig. 8.

Taking into account $F_{\mathrm{r}}$, the following equation can be obtained from Eq. (17),

$m \ddot{x}_{\mathrm{p}}+c \dot{x}_{\mathrm{p}}+k x_{\mathrm{p}}+F_{\mathrm{r}}=F_{\mathrm{p}}$.

On the end effector, friction force, denoted by that pushes the end effector move to the right, is given by

$\left\{\begin{array}{l}F_{\mathrm{r}}^{\prime}=m_{\mathrm{e}} \ddot{x}_{\mathrm{e}} \\ F_{\mathrm{r}}^{\prime}=-F_{\mathrm{r}} \\ x_{\mathrm{e}}=x_{\mathrm{p}}+x_{\mathrm{pe}}\end{array}\right.$

where $x_{\mathrm{e}}$ is the displacement of the end effector, and $x_{\mathrm{pe}}$ is the relative displacement between the end effector and stage. The stick-slip induced friction force $F_{\mathrm{r}}$ can be represented by any one of the aforementioned friction models.

\subsection{Identification of parameters}

The applied voltage to the PEA was a repeating sawtooth wave with an amplitude of $30 \mathrm{~V}$ and frequency of $5 \mathrm{~Hz}$, and the displacements of the end effector were then measured by the displacement sensor. To identify parameters of in a particular friction model, the stick-slip induced friction force $F_{\mathrm{r}}$ in Eq. (25) is substituted by this friction model described in Sect. 3, and based on the experimental data the parameters in this friction model was identified using Simulink and nonlinear fitting (functions in Matlab software). The details for parameter identification technique were discussed in our previous study (Li et al., 2008b). The parameters determined for each friction model are listed in Table 2.

\section{Results with discussion}

The friction force and sliding speed predicted by Coulomb friction model are shown in Figs. 9 and 10, respectively. From Fig. 9 it can be seen that friction is either $F_{\mathrm{c}}$ or $-F_{\mathrm{c}}$. From Figs. 9 and 10 it can be seen that the sign of the friction force is determined by the sign of the sliding speed. The 
Table 2. Parameters determined for each friction model.

\begin{tabular}{llllll}
\hline Parameter & Coulomb & Stribeck & Dahl & LuGre & Elastoplastic \\
\hline$\mu$ & 0.0587 & N/A & N/A & N/A & N/A \\
$k_{v}(\mathrm{~N} / \mathrm{mm})$ & N/A & 40101 & N/A & N/A & N/A \\
$F_{\mathrm{c}}(\mathrm{N})$ & N/A & 4.477 & 3.387 & 2.5 & 2.5 \\
$F_{\mathrm{s}}(\mathrm{N})$ & N/A & 5 & N/A & 3 & 3 \\
$v_{\mathrm{S}}\left(\mathrm{m} \mathrm{s}^{-1}\right)$ & N/A & $1.6 \times 10^{-8}$ & N/A & $1.6 \times 10^{-8}$ & $1.6 \times 10^{-8}$ \\
$\alpha_{0}\left(\mathrm{~N} / \mathrm{mm}^{-1}\right)$ & N/A & N/A & 1674 & 1670 & 1670 \\
$\alpha_{1}\left(\mathrm{Ns} \mathrm{mm}^{-1}\right)$ & N/A & N/A & N/A & 6 & 6 \\
$\alpha_{2}\left(\mathrm{Ns} \mathrm{mm}^{-1}\right)$ & N/A & N/A & N/A & 26 & 26 \\
$Z_{\text {ba }}(\mathrm{mm})$ & N/A & N/A & N/A & N/A & $1 \times 10^{-7}$ \\
\hline
\end{tabular}

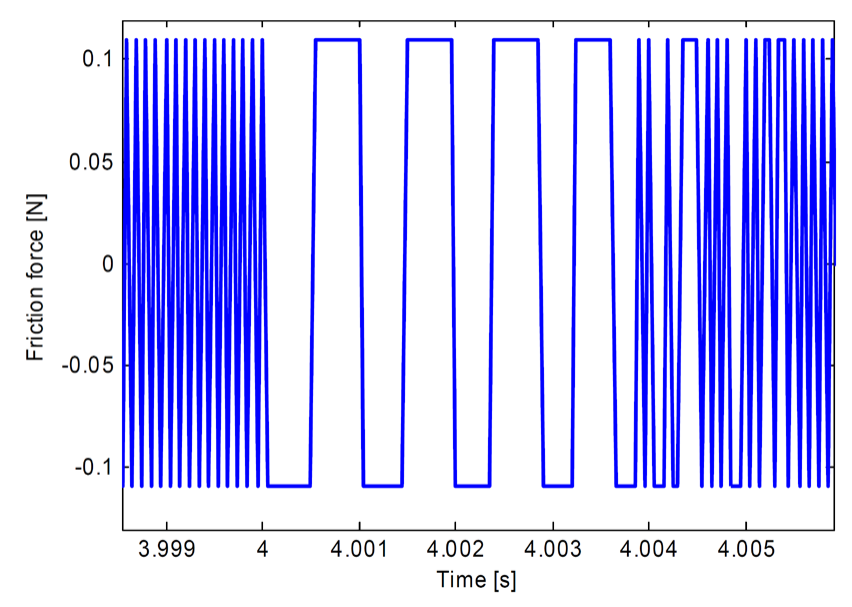

Figure 9. Friction predicted using Coulomb friction model (at around 4th second).

magnitude of $F_{\mathrm{c}}$ or $-F_{\mathrm{c}}$ is dependent on the Coulomb friction coefficient.

It was found that the displacement predicted by the model fits either stick motion or slip motion but fails to fit both of them no matter what friction coefficient is chosen. Figure 11 shows a typical example of the displacement predicted by the model when $\mu=0.0587$. It can be seen from this figure that the displacement in the stick motion period is well predicted, but the displacement predicted for the slip motion period cannot fit the experimental data and leads to huge errors after only a few cycles. The reason for this is analyzed as follows.

As previously discussed, the displacement is related to the friction force using the Newton's second law (see Eq. 25). The friction force in Coulomb friction model is a function of (1) the sign of sliding speed and (2) friction coefficient. The sliding speed (shown in Fig. 10) consists of two parts, i.e. sliding speed in stick motion and sliding speed in slip motion. Notice that the friction coefficient is the only effective variable in the Coulomb friction model. Once the friction coefficient required in stick motion is not the one required in slip motion, the Coulomb friction model will not work for the stick-slip motion system. This problem could be solved

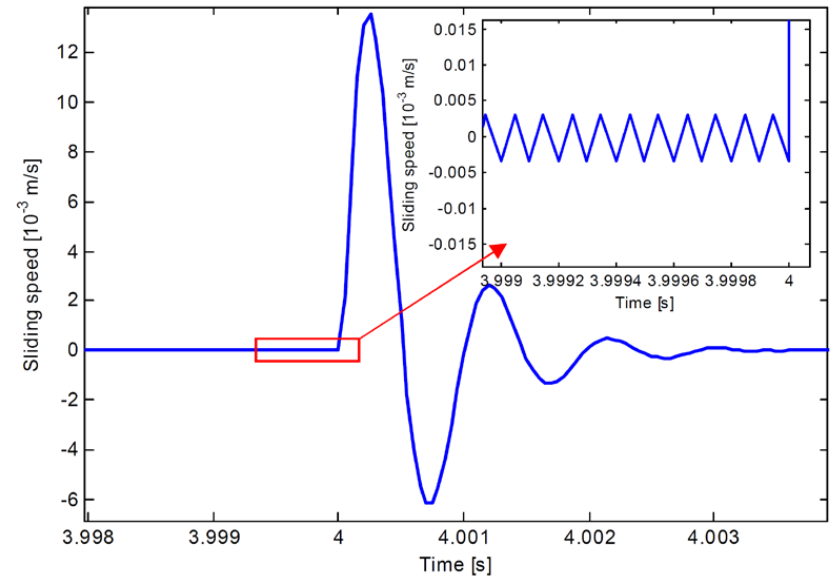

Figure 10. Sliding speed predicted using Coulomb friction model (at around the 4th second).

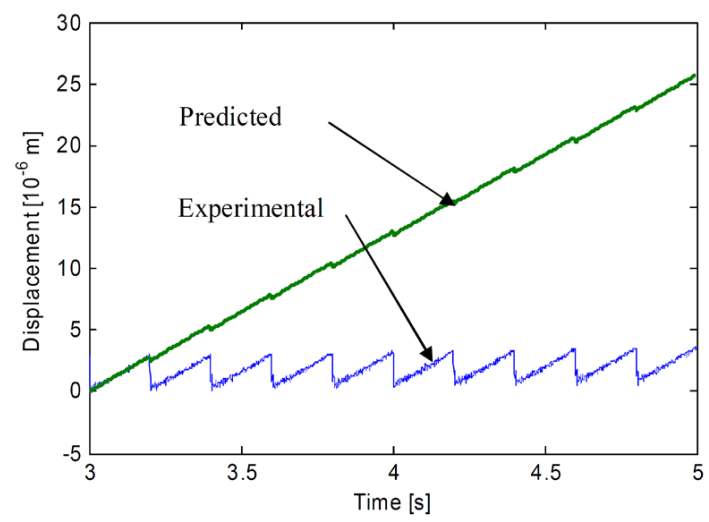

Figure 11. Displacement predicted by Coulomb model $(\mu=0.0587)$.

by considering an ideal situation, as reported in reported in Chang and $\mathrm{Li}$ (1999), where in the stick motion period, there is no sliding; correspondingly, in the stick motion period, the displacement of the end effector is determined by the displacement of the stage. In the slip motion period, the displacement of the end effector is determined by the Coulomb 


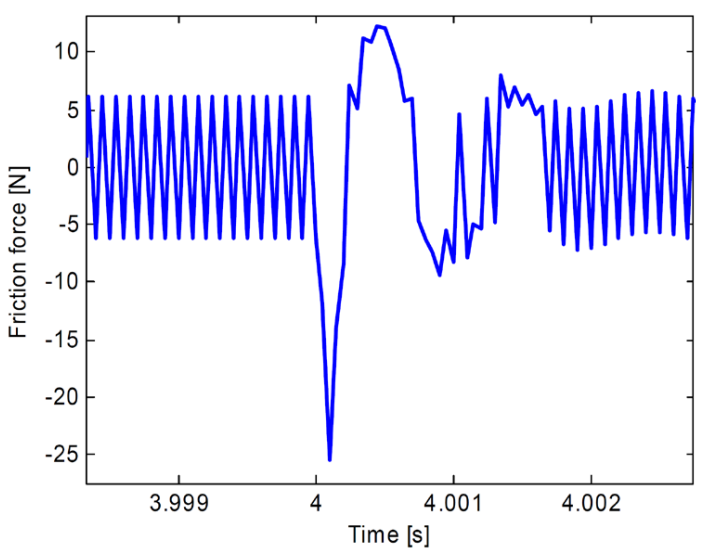

Figure 12. Friction force predicted using Stribeck model (at around the 4th second).

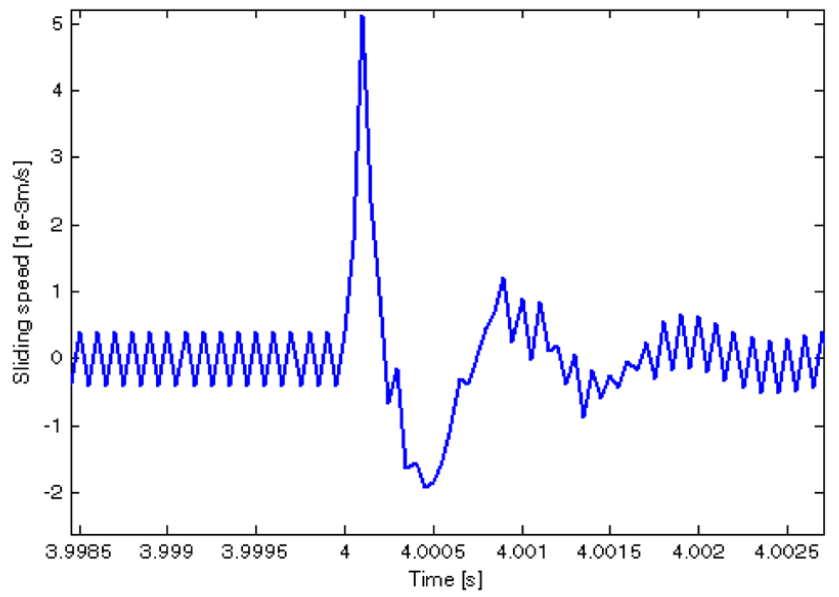

Figure 13. Sliding speed predicted using Stribeck model (at around the 4th second).

friction model. In other words, Coulomb friction model only models friction force in the slip motion period, instead of the entire stick-slip motion cycle. Another problem with the Coulomb friction model is the fluctuation in the sliding speed in stick motion shown in Fig. 10., which is supposed to be zero in theory. The fluctuation is caused by the use of $S g n$ function in the model (see Eq. 1).

\subsection{Results of Stribeck friction model}

The friction force and sliding speed predicted using the Stribeck friction model are shown in Figs. 12 and 13, respectively. The displacement predicted using the Stribeck friction model is shown in Fig. 14 from which it can be seen that Stribeck friction model can well predict friction both in stick and slip motion. Compared to the Coulomb friction model, Stribeck friction model can be used to model the friction force in the stick-slip motion. The reason for this might be that in the Stribeck model friction force is not only depen-

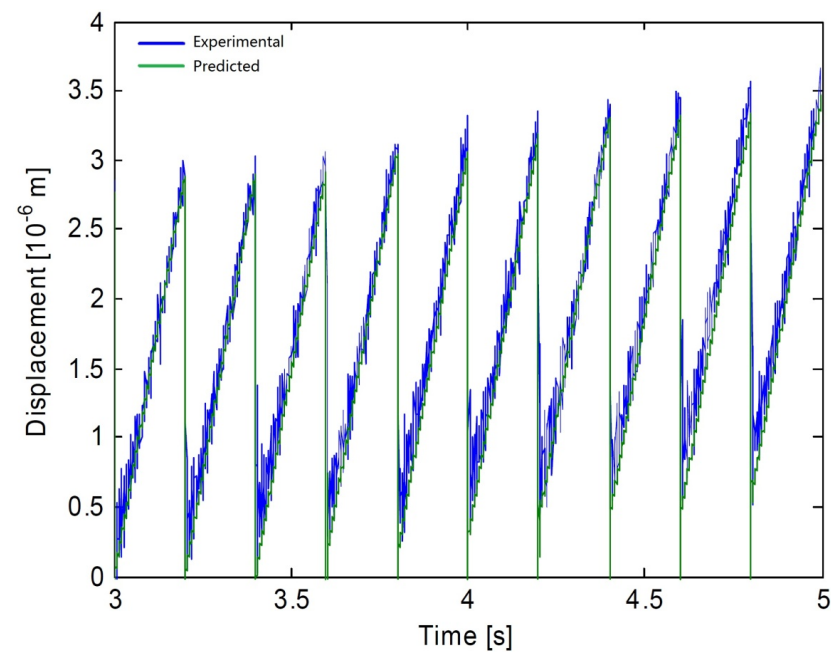

Figure 14. Experimental data and displacements predicted using Stribeck model.

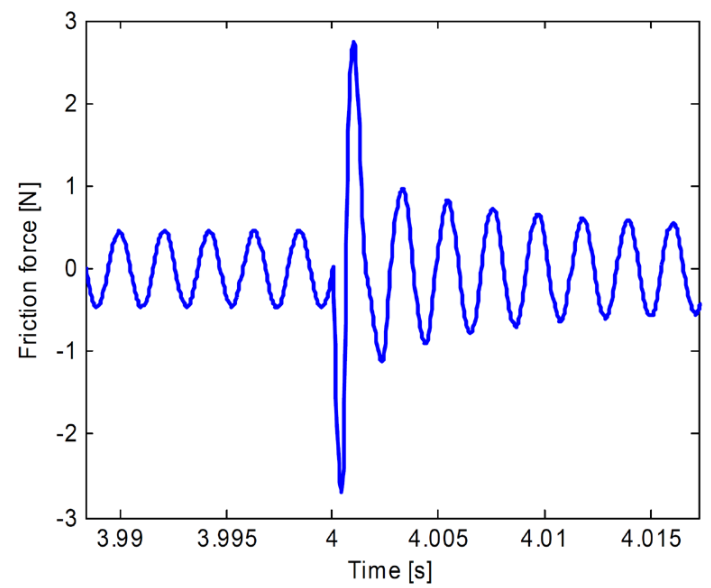

Figure 15. Friction predicted using Dahl model.

dent on the sign of sliding, but also on the sliding speed (see Figs. 12 and 13). From Fig. 12 it can be seen that the friction force predicted by the model fluctuates around zero in the stick motion, which further causes the sliding speed fluctuation (see Fig. 13) and displacement fluctuation (see Fig. 14). Such fluctuation results from the $S g n$ function in the Stribeck model.

\subsection{Results of Dahl model}

The friction force and sliding speed predicted using the Dahl model are shown in Figs. 15 and 16, respectively. From the two figures it can be seen that the friction force is not only dependent on the sign of sliding but also on the sliding speed. The displacement predicted using the Dahl model is shown in Fig. 17 from which it can be seen that Dahl model can well predict friction both in stick and slip motion. To observe the details, a scaled up picture from Fig. 17 (at around 


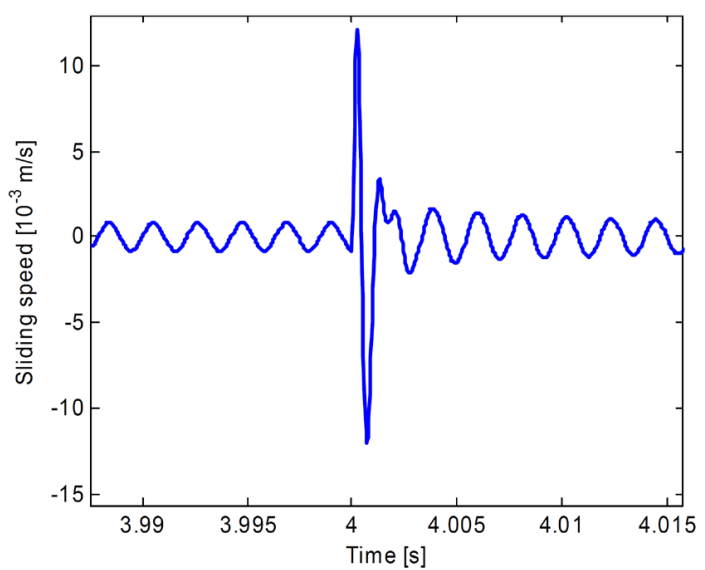

Figure 16. Sliding speed predicted using Dahl model.

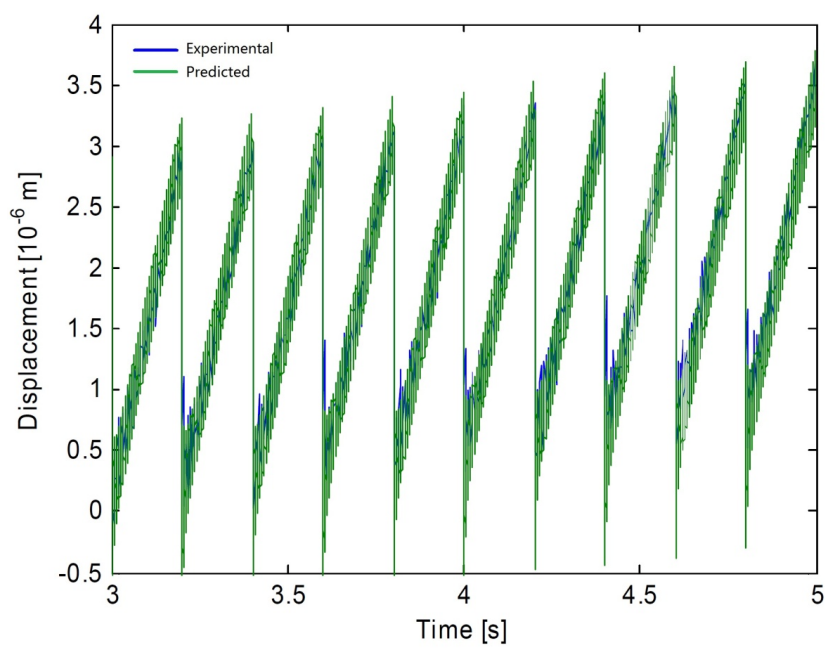

Figure 17. Experimental displacement and displacement predicted using Dahl model.

the 4th second) is shown in Fig. 18. From Fig. 18 it can be seen that the displacement predicted by the Dahl model is fluctuated around the experimental data. This is due to the sliding speed fluctuation, as shown in Fig. 16. The fluctuation (both in friction and sliding speed) results from the function of $S g n$ in the model. Compared to Stribeck model, the fluctuation (both in friction and sliding speed) in the Dahl model seems to be smoother than that in Stribeck model. The reason for this is that the friction force in the Dahl model is the integral of the Sgn function; see Eq. (9).

\subsection{Results of LuGre model}

The friction force and sliding speed predicted using the LuGre model are shown in Figs. 19 and 20, respectively. The displacement predicted using LuGre model is shown in Fig. 21 and its scaled up picture is shown in Fig. 22. From Figs. 19 and 20, it can be seen that the friction force is not

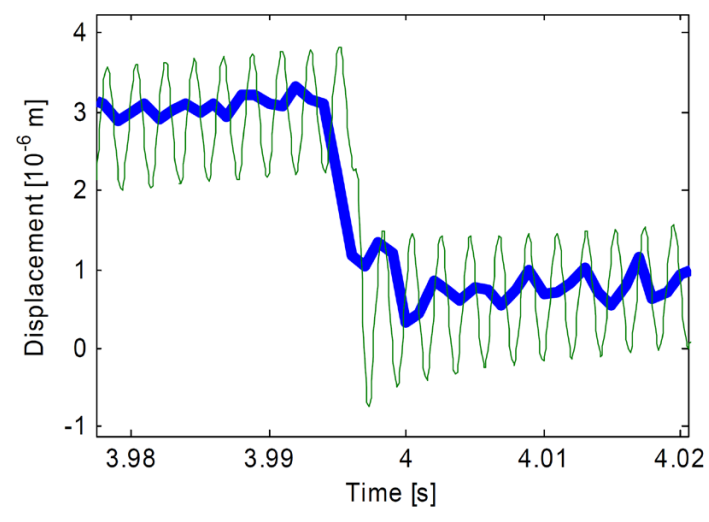

Figure 18. Scaled up picture from Fig. 16 (at around the 4th second).

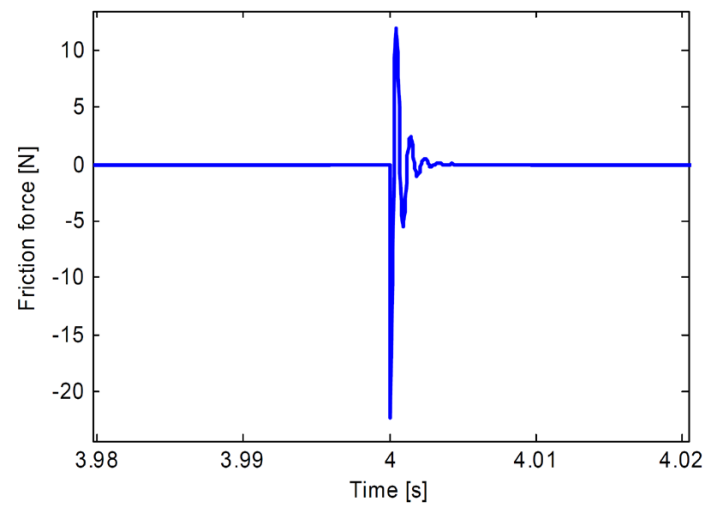

Figure 19. Friction predicted using LuGre model.

only dependent on the sign of sliding but also on the sliding speed, which is constant with the mathematical model. From Figs. 21 and 22 it can be seen that LuGre friction model can well predict friction both in stick and slip motion. Compared to Coulomb model, Stribeck model, and Dahl model (see Figs. 9, 10, 12, 13, 15 and 16), the friction force and sliding speed predicted by the LuGre model for stick motion are zero (see Figs. 19 and 20) instead of fluctuation around zero. From Figs. 21 and 22 it can be seen that the displacement predicted by the model during slip motion does not have any fluctuation, compared to Stribeck and Dahl models which are shown in Figs. 14 and 18, respectively. As we discussed before, the unwanted fluctuations in prediction of the Coulomb model, Stribeck model, and Dahl model are due to the $S g n$ function in the mathematical model. While this problem seems to be completely solved by the LuGre friction model, in which there is no $S g n$ function.

\subsection{Results of the elastoplastic friction model}

The displacement predicted by the elastoplastic model cannot fit the slip motion period no matter what initial parameters are chosen in order to determine the parameters in the 


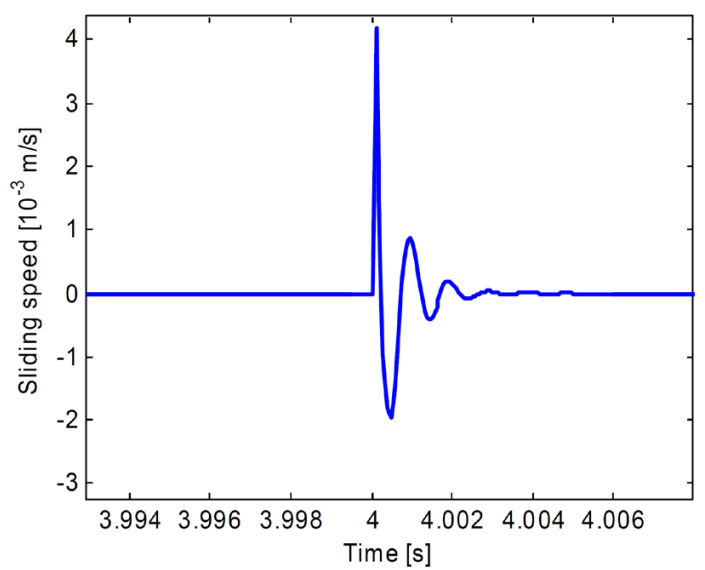

Figure 20. Sliding speed predicted using LuGre model.

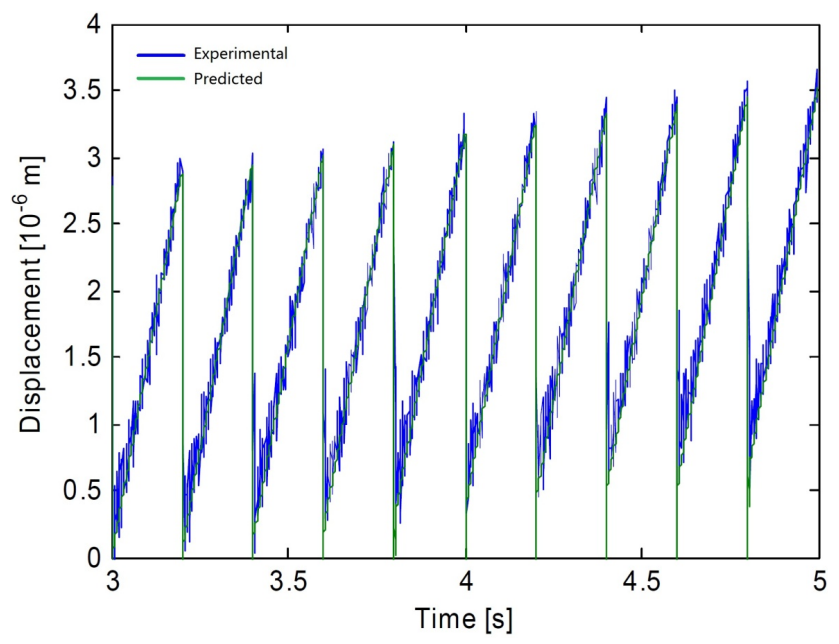

Figure 21. Displacement predicted using LuGre model.

model using the system identification technique. The details are as follows.

- Measure (1): the parameters reported in Dupont et al. (2000) for the elastoplastic model were used as initial values in identification. However, the identification results (not shown in this paper) show that the displacement predicted by the model cannot fit the experimental data.

- Measure (2): the elastoplastic model was developed based on LuGre model, and it only has one more parameter $Z_{\mathrm{ba}}$ than LuGre model to be identified. $Z_{\mathrm{ba}}$ was initially set as $33 \%$ of $Z_{\mathrm{ss}}$, and the remaining parameters were initially set as the same as those in LuGre model. The identification results (not shown in this paper) show that the displacement predicted by the model still cannot fit the experimental data.

- Measure (3): similar with Step (2), $Z_{\mathrm{ba}}$ was initially set as $33 \%$ of $Z_{\mathrm{ss}}$ and determined by identification, but the

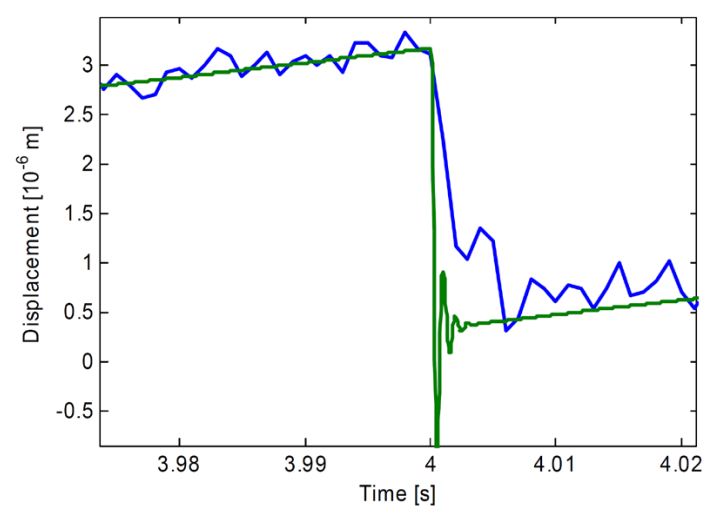

Figure 22. Scaled up picture from Fig. 21 (at around the 4th second).

remaining parameters were assumed (not determined by identification) as the same as those (which were already determined in Sect. 6.4) in LuGre model in order to find out the role of $Z_{\mathrm{ba}}$. The identification results (not shown in this paper) show that the displacement predicted by the model still cannot fit the experimental data regardless of what $Z_{\mathrm{ba}}$ was chosen.

- Measure (4): comparing the elastoplastic model with LuGre model, it can be seen that if $Z_{\mathrm{ss}}$ and $Z_{\mathrm{ba}}$ approach to zero, the eleastoplastic model should turn back to LuGre model. In order to test the elastoplastic model, the parameters $Z_{\mathrm{ss}}$ and $Z_{\mathrm{ba}}$ were set as $Z_{\mathrm{ss}}=0.4 \mathrm{~nm}$ and $Z_{\mathrm{ba}}=0.1 \mathrm{~nm}$, and the remaining parameters were determined as the same as those in LuGre model (which were already determined in Sect. 6.4 and listed in Table 2).

The friction force, sliding speed, and displacement predicted by the model identified in the Measure (4) are shown in Figs. 23-25, respectively. From Figs. 23 and 24 it can be seen that the friction force and sliding speed predicted by the elastoplastic model have the same characteristic with those predicted by LuGre model (see Figs. 19 and 20), i.e. no fluctuations in stick motion. However, the displacement predicted by the elastoplastic model cannot fit the slip motion period, as shown in Fig. 25. According to identification Measure (3) and Measure (4), it seems that $Z_{\mathrm{ba}}$ makes the elastoplastic model can not turn back to LuGre model, which is thus the cause that the elastoplastic model fails to model friction force in the micro stick-slip motion system. The plausible reason for this is discussed as follows.

The elastoplastic model expects that during slip motion, $\operatorname{sgn}(\dot{x})$ should always be equal to $\operatorname{sgn}(z)$ according to Eq. (14); in other words, when $\operatorname{sgn}(\dot{x}) \neq \operatorname{sgn}(z)$, the model predicts that stick motion occurs. The relation between $\operatorname{sgn}(\dot{x})$ and $\operatorname{sgn}(z)$ are shown in Figs. 26 and 27 (which is the amplified figure of Fig. 26) in which 0 represents $\operatorname{sgn}(\dot{x})=\operatorname{sgn}(z)$ and 2 represents $\operatorname{sgn}(\dot{x}) \neq \operatorname{sgn}(z)$. It can be seen that during the stick motion period, $\operatorname{sgn}(\dot{x})$ is 


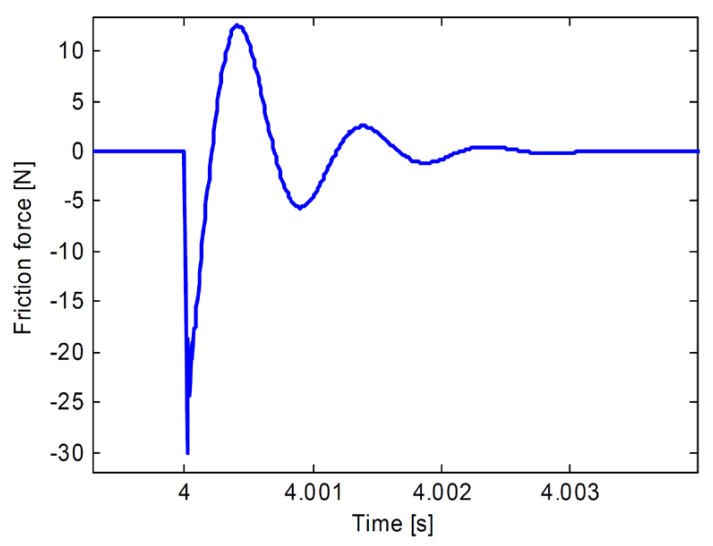

Figure 23. Friction predicted using the elastoplastic model.

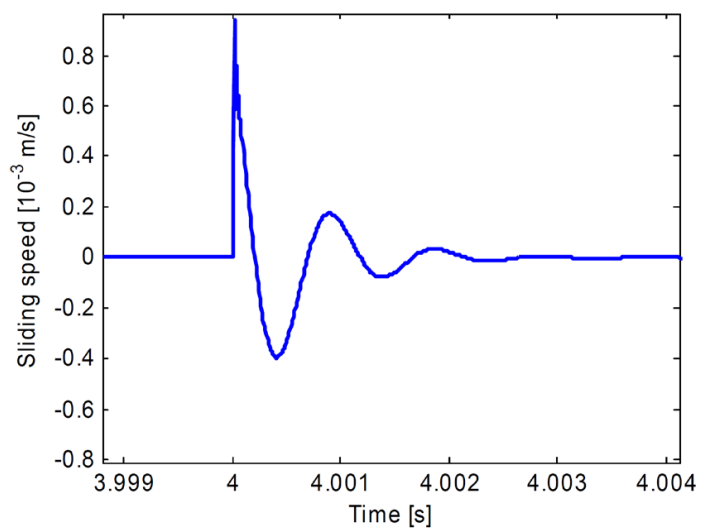

Figure 24. Sliding speed predicted using the elastoplastic model.

not equal to $\operatorname{sgn}(z)$ over the whole period; as such, the model predicts that the stage and end-effector stick "together". During the slip motion period, however, it can be seen that $\operatorname{sgn}(\dot{x})$ is not always equal to $\operatorname{sgn}(z)$; in other words, the model predicts more stick motion than it really has. Therefore, the elastoplastic friction model leads to a larger static friction force and results in no relative motion in the slip motion period, as shown in Fig. 25. The reason that $\operatorname{sgn}(\dot{x})$ is never always equal to $\operatorname{sgn}(z)$ during the slip motion period is discussed as follows.

In stick-slip motion systems such as PE-SSA systems, the stage periodically extends and contract which makes $\operatorname{sgn}(\dot{x})$ reverse when sliding occurs. However, according to the elastoplastic friction model, when $\operatorname{sgn}(\dot{x})$ reverses, i.e. the end effector begins to move from B to A (Fig. 4), the deformation of contact as perities starts to decrease but still remain its initial direction until it reaches the original position, which leads to $\operatorname{sgn}(\dot{x}) \neq \operatorname{sgn}(z)$; correspondingly, the elastaplastic friction model predicts that no sliding occurs according to Eq. (14). This is the reason that the displacement predicted using the elastoplastic model (see Fig. 25) seems not to move at all in the slip motion period, which is not con-

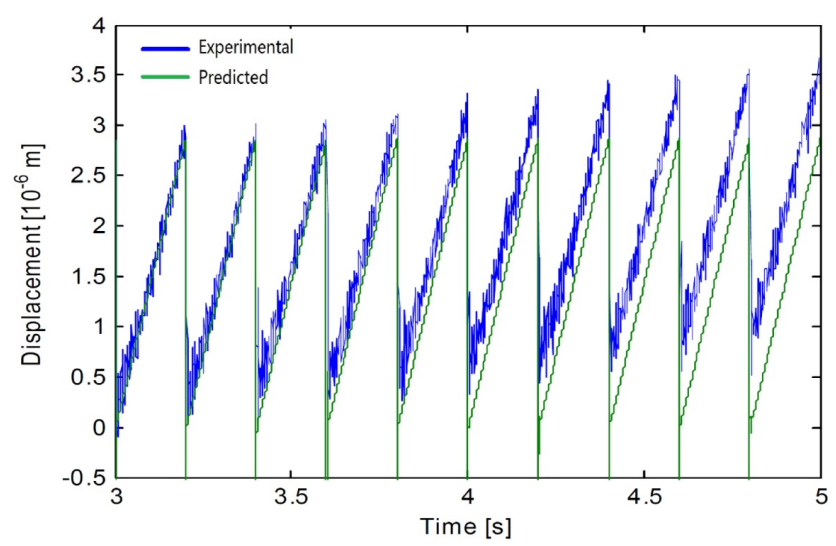

Figure 25. Experimental data and displacement predicted using the elastoplastic model.

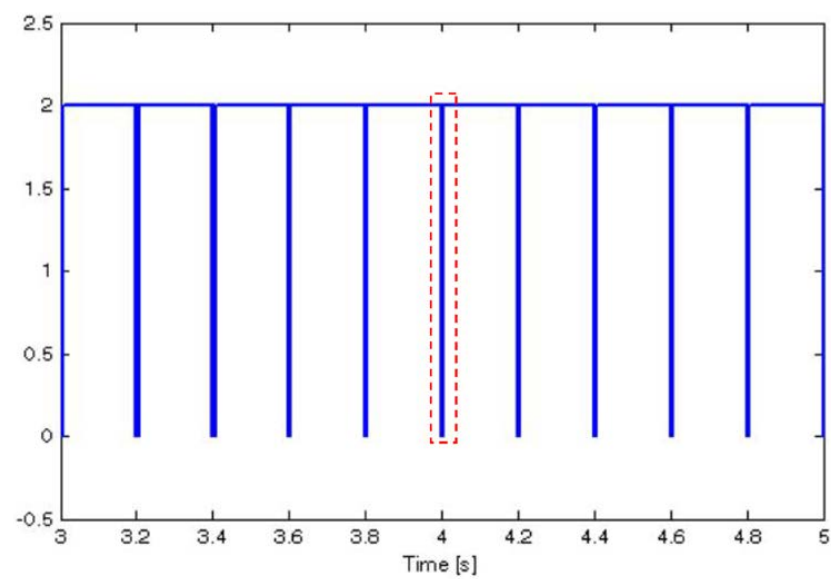

Figure 26. Relation of $\operatorname{sgn}(\dot{x})$ and $\operatorname{sgn}(z)$.

sistent with the observed actual stick-slip motion phenomena.

\subsection{Comparison of Stribeck, Dahl, and LuGre models}

To compare Stribeck, Dahl, and LuGre models in terms of accuracy, an error index representing the deviation between the displacement predicted and experimental data is given by

$e=\frac{1}{n} \sum_{k=1}^{n}\left|e_{k}\right|$

where $\left|e_{k}\right|$ is the absolute value of the error between experimental data and the displacement predicted, $n$ the number of displacement data, and $k=1,2, \ldots, n$.

The error index for each friction model is listed in Table 3.

It is shown that LuGre model has the least error index, and Stribeck model and Dahl model have larger error indexes. The reason is that the displacements predicted by Stribeck model and Dahl model fluctuate around the experimental data (see Figs. 14 and 17 or Fig. 18), which is caused 
Table 3. Error index for friction models.

\begin{tabular}{lccc}
\hline Models & Stribeck & Dahl & LuGre \\
\hline Error index & $0.176 \mu \mathrm{m}$ & $0.232 \mu \mathrm{m}$ & $0.135 \mu \mathrm{m}$ \\
\hline
\end{tabular}

by the $S g n$ function in the two models. LuGre model integrates, pre-sliding friction $\left(\sigma_{0} z\right)$ that is captured by Dahl model and viscous friction $\left(v_{2} \dot{x}\right)$ and Stribeck effect $(g(\dot{x}))$ that are captured by Stribeck friction model, into one single model. Moreover, LuGre model does not have Sgn function and it has no fluctuation in displacement prediction (see Fig. 22). Thus LuGre model results in a better accuracy of friction force prediction in the micro stick-slip motion system.

\section{Conclusions with further discussion}

This paper first reviewed the friction models, i.e. Coulomb, viscous, combined Coulomb and viscous model, Stribeck, Dahl, LuGre, and the elastoplastic friction models. Five of them were applied to model friction force in the micro stickslip motion. Parameters involved in each model were determined using the system identification technique. The performances of these models were compared. The plausible reasons for the difference in performance among these models applied in micro stick-slip motion were discussed.

This study concludes that Coulomb friction model is not adequate for describing the friction in the micro stick-slip motion. Stribeck model, Dahl model and LuGre model can all predict friction force in the micro stick-slip motion, and LuGre model has the best accuracy among the three. The elastoplastic friction model fails to model friction in the micro stick-slip motion because it introduces a larger static friction during the slip motion period that makes two contact surfaces seem to stick together. The failure of the elastoplastic model for the micro stick-slip motion system demonstrates our observation of the so-called "side effect" for complex dynamic systems. In the case of the elastoplastic model, it has more parameters to capture the friction phenomena, especially capturing the so-called "drift" phenomenon when LuGre model is used for the application of positioning system, but the model which resolves the drift problem also brings the side effect in the sense that the same modeling elements, i.e. elastic and plastic deformation zones, causes trouble to model friction force in the micro stick-slip motion.

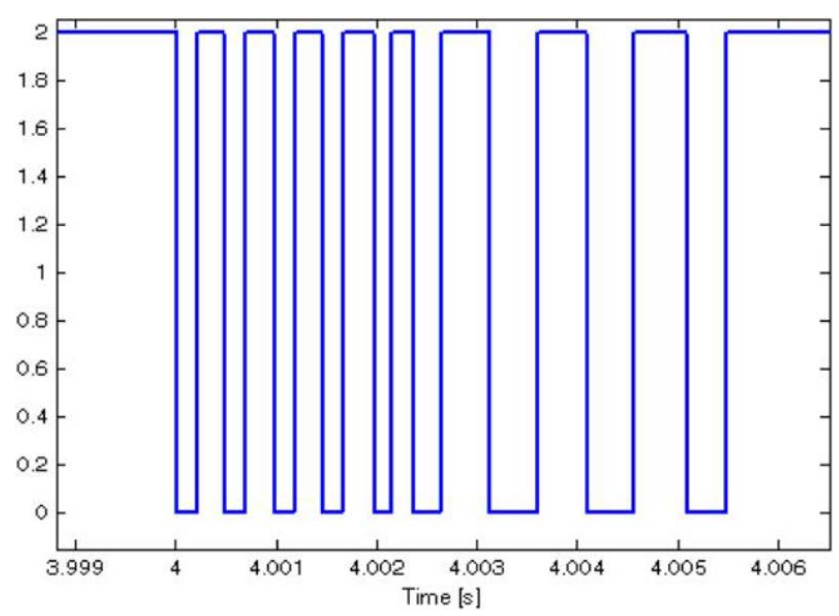

Figure 27. Scaled up picture from Fig. 26.

This study may also demonstrate an idea of using displacement measurement of micro motion system and system identification technique to investigate the dynamic friction in micro motion level. Further validation of this idea calls for some future study. 


\section{Appendix A}

Table A1. Nomenclature.

\begin{tabular}{|c|c|}
\hline$c_{\mathrm{p}}$ & the damping coefficient of PEA, Ns $\mathrm{m}^{-1}$ \\
\hline$c_{\mathrm{S}}$ & the damping coefficient of the stage, $\mathrm{Ns} \mathrm{m}^{-1}$ \\
\hline$F$ & the friction force, $\mathrm{N}$ \\
\hline$F_{\text {app }}$ & the applied force, $\mathrm{N}$ \\
\hline$F_{\mathrm{c}}$ & the Coulomb sliding friction force, $\mathrm{N}$ \\
\hline$F_{\mathrm{N}}$ & the normal load, $\mathrm{N}$ \\
\hline$F_{\mathrm{r}}$ & friction force on the stage, $\mathrm{N}$ \\
\hline$F_{\mathrm{r}}^{\prime}$ & friction force on the end effector, $\mathrm{N}$ \\
\hline$F_{\mathrm{S}}$ & the maximum static friction force, $\mathrm{N}$ \\
\hline$F_{p}$ & the transduced force from the electrical side, $\mathrm{N}$ \\
\hline$g(\dot{x})$ & the Stribeck curve \\
\hline$G(s)$ & the transfer function \\
\hline$i$ & an exponent \\
\hline$j$ & the Stribeck shape factor \\
\hline$K$ & the amplified coefficient, $\mathrm{m} \mathrm{v}^{-1}$ \\
\hline$k_{\mathrm{p}}$ & the stiffness of PEA, $\mathrm{N} \mathrm{m}^{-1}$ \\
\hline$k_{\mathrm{S}}$ & the stiffness of stage, $\mathrm{N} \mathrm{m}^{-1}$ \\
\hline$k_{\mathrm{v}}$ & the viscous coefficient, $\mathrm{Ns} \mathrm{m}^{-1}$ \\
\hline$m_{\mathrm{p}}$ & the mass of PEA, $\mathrm{kg}$ \\
\hline$m_{\mathrm{S}}$ & the mass of stage, $\mathrm{kg}$ \\
\hline os & the overshoot of a step response \\
\hline$T_{\mathrm{em}}$ & the electromechanical transducer ratio, $\mathrm{N} \mathrm{v}^{-1}$ \\
\hline$T_{\mathrm{p}}$ & the peak time of a step response, $s$ \\
\hline$u_{\mathrm{p}}$ & the applied voltage on the PEA, V \\
\hline$v_{\mathrm{S}}$ & the Stribeck velocity, $\mathrm{m} \mathrm{s}^{-1}$ \\
\hline$x$ & the relative displacement, $\mathrm{m}$ \\
\hline$\dot{x}$ & the sliding speed, $\mathrm{m} \mathrm{s}^{-1}$ \\
\hline$x_{\mathrm{e}}$ & the displacement of the end effector, $\mathrm{m}$ \\
\hline$x_{\mathrm{p}}$ & the displacement of the PEA, $m$ \\
\hline$x_{\mathrm{pe}}$ & $\begin{array}{l}\text { the relative displacement between the end } \\
\text { effector and stage, } \mathrm{m}\end{array}$ \\
\hline$z$ & the average bristle deflection, $\mathrm{m}$ \\
\hline$z_{\text {ba }}$ & the stiction zone, $\mathrm{m}$ \\
\hline$z_{\mathrm{ss}}$ & $\begin{array}{l}\text { the parameter for transition from sticking to } \\
\text { slipping, } m\end{array}$ \\
\hline$\alpha(z, \dot{x})$ & function of elastic and plastic deformation \\
\hline$\alpha_{m}(*)$ & the function of transition from sticking to slipping \\
\hline$\mu$ & Coulomb friction coefficient \\
\hline$\xi$ & the damping ratio \\
\hline$\omega_{\mathrm{n}}$ & the natural frequency, $\operatorname{rad~s}^{-1}$ \\
\hline$\sigma_{0}$ & the stiffness of the bristles, $\mathrm{N} \mathrm{mm}^{-1}$ \\
\hline$\sigma_{1}$ & the damping coefficient of the bristles, $\mathrm{Ns} \mathrm{mm}^{-1}$ \\
\hline$\sigma_{2}$ & the viscous friction coefficient, $\mathrm{Ns} \mathrm{mm}^{-1}$ \\
\hline
\end{tabular}


Acknowledgements. The authors want to thank J. W. Li, Q. S. Zhang for their performing the experiments. This work has been supported by The Natural Sciences and Engineering Research Council of Canada (NSERC), National Natural Science Foundation of China (NSFC) (grant number: 51375166) and China Scholarship Council (CSC), and these organizations are thanked for the support.

Edited by: A. Barari

Reviewed by: P. Ouyang and Z. Bi

\section{References}

Adriaens, H. J. M. T. A., De Koning, W. L., and Banning, R.: Modeling piezoelectric actuators, IEEE/ASME T. Mechatron., 5, 331-341, 2000.

Andersson, S., Söderberg, A., and Björklund, S.: Friction models for sliding dry, boundary and mixed lubricated contacts, Tribol. Int., 40, 580-587, 2007.

Armstrong-Helouvry, B.: Stick slip and control in low-speed motion. IEEE T. Automat. Contr., 38, 1483-1496, 1993.

Chang, S. H. and Li, S. S.: A high resolution long travel frictiondriven micropositioner with programmable step size, Rev. Scient. Instrum., 70, 2776-2782, 1999.

Canudas de Wit, C., Olsson, H., Åström, K. J., and Lischinsky, P.: A New Model for Control of Systems with Friction, IEEE T. Automat. Contr., 40, 419-425, 1995.

Dahl, P. R.: A solid friction model, Technical Report Tor0158(3107-18)-1, The Aerospace Corporation, EI Segundo, CA, 1968.

Dupont, P., Armstrong, B., and Hayward, V.: Elasto-plastic friction model: contact compliance and stiction, Proc. Am. Control Conf., Chiacago, IL, 1072-1077, 2000.

Kang, D.: Modeling of the Piezoelectric-Driven Stick-Slip Actuators, Thesis of Master of Science, University of Saskatchewan, Saskatchewan, Canada, 2007.
Lampaert, V., Swevers, J., and Al-Bender, F.: Modification of the Leuven integrated friction model structure, IEEE T. Automat. Contr., 47, 683-687, 2002.

Li, J. W., Yang, G. S., Zhang, W. J., Tu, S. D., and Chen, X. B.: Thermal effect on piezoelectric stick-slip actuator systems, Rev. Scient. Instrum., 79, 046108, doi:10.1063/1.2908162, 2008a.

Li, J. W., Chen, X. B., An, Q., Tu, S. D., and Zhang, W. J.: Friction models incorporating thermal effects in highly precision actuators, Rev. Scient. Instrum., 80, 045104, doi:10.1063/1.3115208, 2008b.

Li, J. W., Zhang, W. J., Yang, G. S., Tu, S. D., and Chen, X. B.: Thermal-error modeling for complex physical systems: the-stateof-arts review, Int. J. Adv. Manufact. Technol., 42, 168-179, 2009.

Makkar, C., Hu, G., Sawyer, W. G., and Dixon, W. E.: LyapunovBased Tracking Control in the Presence of Uncertain Nonlinear Parameterizable Friction, IEEE T. Automat. Contr., 52, 19881994, 2007.

Morin, A.: New friction experiments carried out at Metz in 18311833, Proc. French Roy. Acad. Sci., 4, 1-128, 1833.

Stribeck, R.: Die wesentlichen Eigenschaften der Gleit- und Rollenlager, Zeitschrift des Vereins Deutscher Ingenieure, Duesseldorf, Germany, 36 Band 46, 1341-1348, 1432-1438, 1463-1470, 1902.

Swevers, J., Al-Bender, F., Ganseman, C. G., and Prajogo, T.: An integrated friction model structure with improved presliding behaviour for accurate friction compensation, IEEE T. Automat. Contr., 45, 675-686, 2000.

Zhang, W. J., Ouyang, P. R., and Sun, Z.: A novel hybridization design principle for intelligent mechatronics systems, Proceedings of International Conference on Advanced Mechatronics (ICAM2010), Osaka University Convention Toyonaka, Japan, 46, 2010.

Zhang, Z. M., An, Q., Zhang, W. J., Yang, Q., Tang, Y. J., and Chen, X. B.: Modeling of directional friction on a fully lubricated surface with regular anisotropic asperities, Meccanica Springer Netherlands, 2011. 